\title{
CONTABILIDADE FUTEBOL CLUBE: UMA REVISÃO DA LITERATURA CONTÁBIL SOBRE CLUBES DE FUTEBOL
}

\author{
${ }^{1}$ Thiago Bruno de Jesus Silva \\ ${ }^{2}$ Rodrigo Rengel \\ ${ }^{3}$ Allison Manoel de Sousa \\ ${ }^{4}$ Carlos Eduardo Facin Lavarda
}

\section{Resumo}

Objetivo: Esta pesquisa objetiva analisar as características das investigações internacionais e nacionais em relação a um fragmento de literatura sobre a literatura Contábil em Clubes de Futebol, ao ter como intenção a geração de conhecimento e identificação de lacunas para apontar possibilidades de futuras investigações.

Método: Empregou-se o Knowledge Development Process-Constructivist (ProKnow-C) para fins de orientação.

Originalidade/Relevância: Identificaram-se oportunidades de novas pesquisas na área de clubes de futebol estão abertas na literatura, bem como, com base na literatura analisada, a necessidade de melhoria na gestão dos clubes de futebol, voltada tanto ao desempenho esportivo quanto financeiro e econômico.

Resultados: Como resultados, constatou-se, (i) necessidade de análise sob a lentes de outras teorias de vertentes distinta da econômica e sociológica; (ii) identificar as características organizacionais, como expertise do gestor (Presidente), sistema de controle gerencial; (iii) identificar como os jogadores se planejam para sua aposentaria; (iv) refletir quanto abertura de capital para negociar ações ao reconhecer possibilidade de captação de novos recursos/investimentos.

Contribuições teóricas e sociais: Com base nas lacunas identificadas, entende-se a necessidade de abertura dos clubes de futebol para pesquisas acadêmica, o que certamente contribuirão para o avanço acadêmico e também em âmbito profissional. A maioria das pesquisas internacionais apresenta discussões sobre o comportamento do preço de ações dos clubes. Torna-se relevante refletir quanto abertura de capital para negociar ações para captação de novos recursos/investimentos. Destaca-se que evidenciem os relatórios financeiros de forma regular e um meio que possibilite fácil obtenção aos pesquisadores e ao público de forma geral.

Palavras-chave: Contabilidade. Clubes de Futebol. Revisão de Literatura.

${ }^{1}$ Universidade Federal da Grande Dourados - UFGD, Mato Grosso do Sul, (Brasil). E-mail: thiagobsilva@ufgd.edu.br Orcid id: https://orcid.org/0000-0002-1128-6601

${ }^{2}$ Universidade Federal de Santa Catarina - UFSC, Santa Catarina, (Brasil). E-mail: rengel.rodrigo@ hotmail.com Orcid id: https://orcid.org/0000-0003-1767-1655

${ }^{3}$ Universidade Federal de Santa Catarina - UFSC, Santa Catarina, (Brasil). E-mail: allison.msousa@gmail.com Orcid id: https://orcid.org/0000-0002-5959-6078

${ }^{4}$ Universidade Federal de Santa Catarina - UFSC, Santa Catarina, (Brasil). E-mail: elavarda@ gmail.com Orcid id: https://orcid.org/0000-0003-1498-7881 


\title{
ACCOUNTING SOCCER CLUB: A REVIEW OF ACCOUNTING LITERATURE ABOUT FOOTBALL CLUBS
}

\begin{abstract}
Objective: This research aims to analyze the characteristics of international and national investigations in relation to a fragment of literature on the accounting literature in Football Clubs, with the intention of generating knowledge and identifying gaps to point out possibilities for future investigations.
\end{abstract}

Methodology: Knowledge Development Process-Constructivist (ProKnow-C) used for guidance purposes.

Originality and Relevance: New research opportunities in the field of football clubs had identified and are open in the literature, as well as, based on the literature analyzed, the need to improve the management of football clubs, focused on both sports and financial performance economic.

Results: As a result, it was found: (i) the need for analysis under the lens of other theories from different aspects of economic and sociological; (ii) identify organizational characteristics, such as manager (President) expertise, management control system; (iii) identify how players plan for their retirement; (iv) reflect on the IPO to trade shares by recognizing the possibility of raising new funds / investments.

Theoretical and social contributions: Based on the identified gaps, it is understood the need to open football clubs for academic research, which will certainly contribute to academic advancement and in the professional field. Most international research presents discussions on club stock price behavior. It is relevant to reflect on the IPO to trade shares to raise new funds / investments. Finally, it is a good idea that they make financial reporting regularly and a means of making it easily available to researchers and the public.

Keywords: Accounting. Football Clubs. Literature review. 


\section{CONTABILIDAD DEL CLUB DE FÚTBOL: UNA REVISIÓN DE LA LITERATURA CONTABLE EN LOS CLUBES DE FÚTBOL}

\section{Resumen}

Objetivo: Esta investigación tiene como objetivo analizar las características de las investigaciones internacionales y nacionales en relación con un fragmento de literatura sobre literatura contable en clubes de fútbol, con la intención de generar conocimiento e identificar brechas para señalar las posibilidades de futuras investigaciones.

Método: Se utilizó el Proceso de Desarrollo del Conocimiento-Constructivista (ProKnow-C) con fines de orientación.

Originalidad / Relevancia: se han identificado nuevas oportunidades de investigación en el campo de los clubes de fútbol y están abiertas en la literatura, así como, según la literatura analizada, la necesidad de mejorar la gestión de los clubes de fútbol, centrada en el rendimiento deportivo y financiero. económico

Resultados: Como resultado, se encontró: (i) la necesidad de análisis bajo la lente de otras teorías de diferentes líneas de economía y sociología; (ii) identifique las características de la organización, como la experiencia del gerente (presidente), el sistema de control de gestión; (iii) identificar cómo los jugadores planean su retiro; (iv) reflexionar sobre la OPV para negociar acciones reconociendo la posibilidad de recaudar nuevos fondos / inversiones.

Contribuciones teóricas y sociales: en base a las brechas identificadas, se entiende la necesidad de abrir clubes de fútbol para la investigación académica, lo que sin duda contribuirá al avance académico y también en el campo profesional. La mayoría de las investigaciones internacionales presentan discusiones sobre el comportamiento del precio de las acciones del club. Es relevante reflexionar sobre la IPO para intercambiar acciones para recaudar nuevos fondos / inversiones. Es de destacar que hacen que los informes financieros estén disponibles regularmente y un medio que permite a los investigadores y al público en general obtenerlos fácilmente.

Palabras clave: Contabilidad. Clubes de fútbol. Revisión de literatura. 


\section{INTRODUÇÃO}

O futebol é uma atração cultural e uma prática desportiva que chama a atenção do público em todo mundo e que é responsável pela geração de reflexos na esfera econômica (Holanda et al., 2012). Deste modo, não é apenas mais um jogo de esportes, é uma parte fundamental da indústria global. Os clubes de futebol transformaram o jogo em um negócio de bilhões de dólares pela comercialização do jogo em si, de jogadores e todos os produtos relacionados com jogos, como nomes, estádios, camisas, entre outros (Sakinc, Acikalin \& Soyguden, 2017).

Apesar de ser considerado como atividade, muito embora enfoca no entretenimento, com menção à grande admiração dos torcedores diante do seu clube do coração, o futebol é considerado como uma grande empresa, no qual é responsável por revelação de jogadores ditos como futuras promessas, formar craques de futebol, valorizar atletas contratados e criar produtos que elevam a marca dos clubes, o que impacta na geração de recursos na Europa e no Brasil (Dantas \& Boente, 2011). Destarte, pode-se observar a evolução do futebol como um negócio, com a inclusão de atores (empresário, organizações, mídia e clientes) em uma busca constante por desempenho financeiro (Costa et al., 2018).

Neste contexto, a contabilidade está envolvida em todo este processo para gestão dos clubes de futebol, no qual estão focadas na provisão de serviços, interface externa, planejamento estratégico e sistemas de controle e de informação para subsidia-los a obter desempenho satisfatório (Abosag et al., 2012). Ademais, Oprean e Oprisor (2014) exemplificam o papel da contabilidade com os clubes de futebol, onde tem-se os registros dos contratos dos jogadores que é enquadrado como contabilidade de recursos humanos, as técnicas de contabilidade fornecem representações financeiras e os padrões contábeis que são aplicados.

Contudo, pouco se conhece a respeito das contribuições cientificas desenvolvidas entre a literatura contábil em estudos voltados aos clubes de futebol. Abordar esta relação desenha um problema de pesquisa, ao que tudo indica, ainda não explorado. Em virtude disto e dada a importância da contabilidade às organizações, como os clubes de futebol, surge o seguinte problema de pesquisa: Como o conhecimento resultante da análise da literatura sobre Contabilidade pode ser sintetizado em contribuições nos Clubes de Futebol? Nesse ínterim, o objetivo foi analisar as características das investigações internacionais e nacionais em relação a um fragmento de literatura sobre a literatura Contábil em Clubes de Futebol, ao ter como intenção a geração de conhecimento e identificação de lacunas para apontar possibilidades de futuras investigações. Para conduzir o processo de seleção das publicações, adotou-se o Knowledge Development Process-Constructivist (Proknow-C) (Dutra et al., 2015 Thiel, Ensslin \& Ensslin, 2017) como instrumento teórico de intervenção devido à sua abordagem científico-construtivista, alinhada ao objetivo da pesquisa e a seu processo estruturado.

Essa investigação se justifica quanto à importância, originalidade e viabilidade (Castro, 1977). A importância é devido à contribuição à comunidade científica e prática que estuda clubes de futebol com o intuito de destacar, em um único estudo, a investigação do conteúdo dos estudos ao longo dos anos, as instituições responsáveis e as principais críticas encontradas em um conjunto de obras internacionais (artigos), reconhecidas cientificamente, e relevantes ao esclarecer as bases que informam a temática e o que seus resultados representam. Considera-se original por não terem, na literatura consultada, investigações que se propusessem a apresentar as características desses estudos. Nesse sentido, percebe-se ser viável pelo acesso aos dados, ao considerar que os artigos analisados são buscados no Portal de Periódicos da CAPES e por demandar apenas o envolvimento dos pesquisadores para análise dos artigos.

\section{PROCEDIMENTOS METODOLÓGICOS}

Esta pesquisa caracteriza-se quanto ao problema como pesquisa qualitativa, quanto ao objeto como exploratória e descritiva quanto ao objetivo. Perante aos procedimentos, classifica-se como uma pesquisa bibliográfica por ser elaborada com base em artigos científicos já publicados em periódicos. Ainda se classifica como sendo uma pesquisa-ação, devido ao fato de que os pesquisadores estão envolvidos com o problema, tanto no processo de busca, quanto na análise crítica dos artigos do Portfólio Bibliográfico (PB) (Prodanov \& Freitas, 2013).

Como instrumento de intervenção, optou-se pelo ProKnow-C haja vista que o objetivo da pesquisa é desenvolver aos pesquisadores conhecimento sobre o fragmento da literatura de contabilidade em clubes de futebol. O ProKnow-C é composto por três etapas, sendo: (i) seleção do portfólio bibliográfico; (ii) bibliometria; (iii) formulação da pergunta e objetivos da pesquisa (Valmorbida et al., 2016; Dutra et al., 2015). A primeira etapa é a Seleção do PB. Os resultados da operacionalização desta etapa estão demonstrados na Figura 1. 


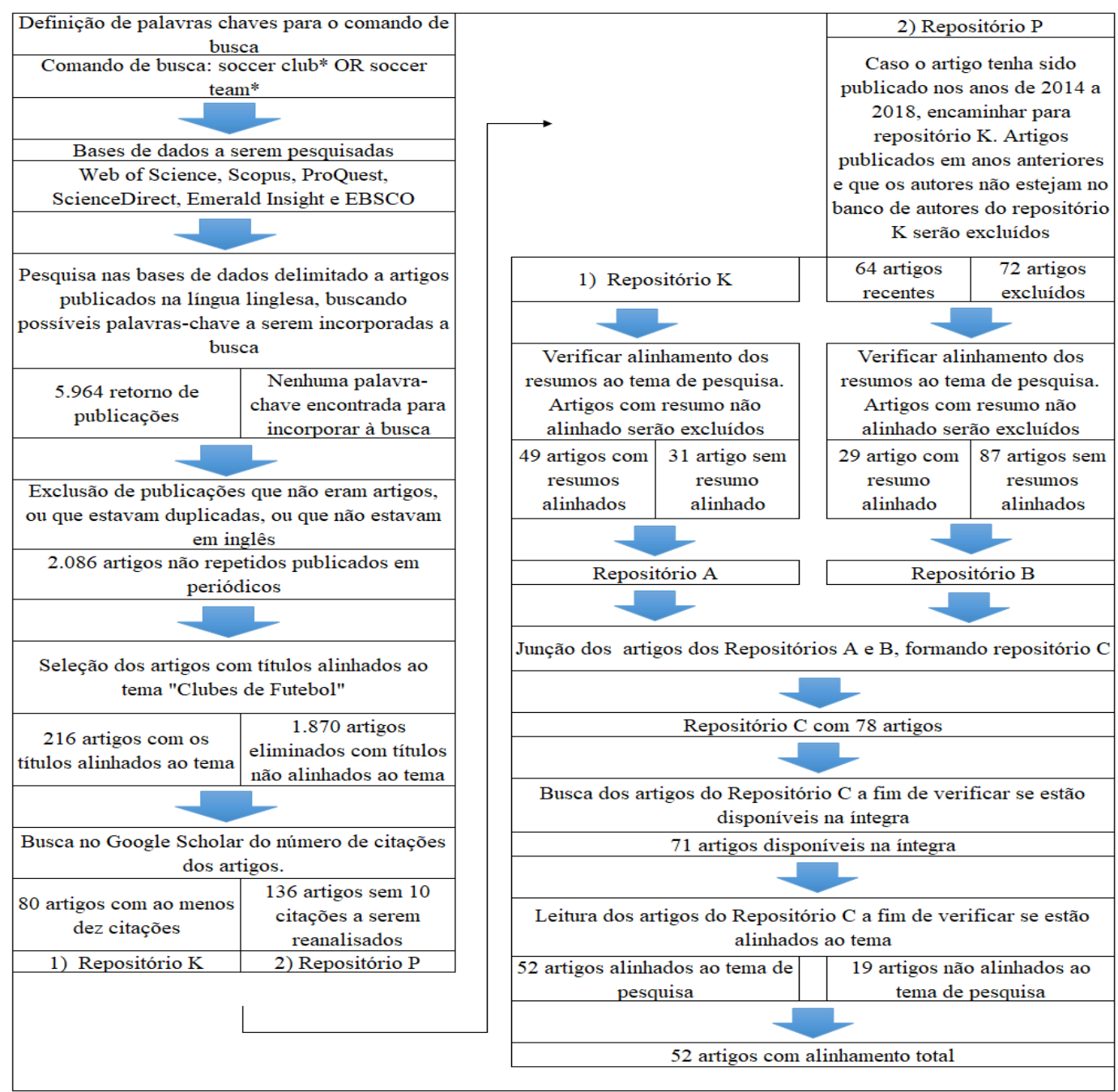

Figura 1. Processo Completo de Seleção do Portfólio Bibliográfico

O acesso à estas bases de dados, foi possibilitado devido ao login e senha disponibilizados pela Universidade Federal de Santa Catarina (UFSC). Optouse ainda pelas seguintes delimitações: (i) artigos publicados em periódicos científicos sem delimitação temporal; e (ii) comando de busca pesquisado nos títulos, resumos e palavras-chave. A pesquisa foi realizada no dia 11 de setembro de 2018.

O alinhamento de cada etapa seguiu os critérios de ser relacionado à contabilidade em clubes de futebol. Destarte, contempla-se o PB com 52 artigos científicos referentes ao fragmento da literatura de Clubes de Futebol alinhados à contabilidade. Após a etapa de coleta dos dados, realizaram-se análises bibliométricas dos dados para proporcionar conhecimento aos pesquisadores sobre determinadas características do PB (Dutra et al., 2015; Thiel, Ensslin \& Ensslin, 2017; Ensslin et al., 2014; Valmorbida et al. 2014). A análise dos dados bibliométricos foi com base em variáveis básicas, na qual são identificados os autores prolíficos do tema, bem como redes de autores, redes de instituições e os países destas, as revistas que os artigos do PB foram publicados, a identificação da área de pesquisa (contabilidade gerencial ou financeira), a composição do $\mathrm{PB}$ em relação a estudos empíricos e teóricos, a evolução temporal dos estudos, além da identificação das teorias utilizadas nos estudos. Também se analisa com base em variáveis avançadas da análise bibliométrica, as limitações dos estudos bem como as sugestões de pesquisas futuras.

\section{REFERENCIAL TEÓRICO}

O futebol é a modalidades esportiva mais popular no Brasil (Marçal, 2018). Consiste em uma prática esportiva que surgiu no século XIX, na qual foi difundida pelo mundo no fím do século XIX e início do século XX. Nesse contexto, surgiram clubes de futebol que se profissionalizaram ao longo do tempo (Senaux, 2008), contudo, Nazi e Amboni (2018) 
destacam que com a intensificação da globalização e da criação de legislações específicas para as agremiações futebolísticas gerou a necessidade da profissionalização da gestão dos clubes de futebol. Essa profissionalização fez com que o futebol passasse de associações sem fins lucrativos para fins lucrativos, na qual provocou mudanças, principalmente, quanto ao processo orçamentário e gestão financeira (Uluyol, 2014). Dessa forma, a profissionalização da gestão dos clubes de futebol fez com que houvesse mudanças, sobretudo, em tornar o ambiente mais institucionalizado (Gammelsaeter \& Jakobsen, 2008).

Nesse sentido, os clubes de futebol não têm como objetivo, apenas obter lucros, mas também de ter outros objetivos, tais como: não perder jogos, mesmo com consequências ruins ao desempenho apresentado por meio dos relatórios financeiros do clube (Vamplew, 1982; Ascari \& Gagnepain, 2007). Mesmo assim, Santos, Dani e Hein (2016) e Cunha, Santos e Haveroth (2017) destacam que os clubes de futebol movimentam valores monetários relevantes e que para serem competitivos devem ter aumento nas receitas, impulsionado a partir da conquista de campeonatos. Na mesma linha, Magaz-Gonzalez, Mallo-Fernández e Fanjul-Suárez (2017), colocam que os clubes tendem a estar na principal divisão do campeonato nacional, uma vez que se tem maior visibilidade e arrecadação do que os clubes que não fazem parte desta divisão.

Nessa perspectiva, os clubes podem adotar estratégias que possam contribuir para o aumento do desempenho financeiro do clube, na qual uma destas consiste em consolidar a marca. Couvelaere e Richelieu (2005) discorrem que os clubes que estão em ligas com recursos financeiros escassos e visibilidade reduzida podem realizar estratégias com foco na marca para o aumento das receitas a partir da maior confiança dos seus clientes e fortificar relações pessoais e emocionais com seus torcedores. Por sua vez, Dias e Rossi (2017) destacam uma forma consolidar a marca dos clubes de futebol consiste em realizar parcerias entre patrocinadores e os clubes, na qual isto tem efeitos benéficos, uma vez que os clubes têm maior desempenho e fortalecimento da marca no ambiente institucional. Em complemento, Costa et al. (2018), destacam que a melhor comunicação do clube com o público externo agrega valor a imagem da agremiação e consequentemente a sua marca.

Ainda no âmbito interno dos clubes de futebol, Fainshmidt, Smith e Guldiken (2017) enfatizam que os gerentes devem se preocupar com os recursos humanos dos clubes, dado a sua importância no desempenho organizacional. $\mathrm{Na}$ mesma linha, Velema (2018) apresenta que o capital humano é importante para o clube de futebol, sobretudo, porque afetam o valor de mercado dos jogadores. Contudo, os altos salários dos jogadores podem prejudicar a solvência financeira e o capital de giro dos clubes, dessa forma, os gerentes devem planejar os gastos com salários, sobretudo, dos jogadores (Souza, Leite \& Seeman, 2017; Andreff, 2007). Em outra perspectiva, Brandes, Franck e Nüesch (2008) argumentam que o pagamento de altos salários para jogadores, amplamente conhecidos, aumenta as receitas e fortalece a marca do clube.

Por sua vez, ao considerar o salário dos jogadores Oprean e Oprisor (2014), destacam que a escolha contábil quanto a mensuração do valor de mercado do jogador pode impactar os relatórios financeiros, na qual argumenta que pode ser um equívoco mensurar o valor de mercado com base nos valores referentes aos salários futuros a serem recebidos pelos jogadores e sugerem que o mais adequado seria a estimativa fundamentada no custo de recrutamento e formação deste profissional. Dessa forma, essas informações podem afetar os relatórios financeiros, que podem ser utilizados pelos investidores, especialmente, no que tange aos clubes de capital aberto.

Os gestores também devem se preocupar com os torcedores, uma vez que estes possuem apreço emocional e, por este motivo tendem a investir no clube (Ruyter \& Wetzels, 2000). De forma complementar, os clubes se tornam uma forma diferente de investimento, uma vez que os preços das ações reagem aos resultados dos jogos (Berument, Ceylan \& Gozpinar, 2006; Palomino, Renneboog \& Zhang, 2009), perspectivas dos torcedores quanto ao resultado da partida (Demirhan, 2013) e informações financeiras (Gannon, Evans \& Goddard, 2006; Zuber et al., 2007).

Em complemento, Haugen e Hervik (2002) apresentam que as informações financeiras, resultados dos jogos, apenas, não explicam a reação dos preços das ações dos clubes de futebol, mas também a qualidade da infraestrutura, localização regional, número de torcedores. Além disso, os clubes de futebol, que são de capital aberto, tem como investidores os seus próprios torcedores, os quais colocam os seus sentimentos pelos clubes quanto a compra e venda de ações dos clubes, sobretudo, de três a cinco dias após algum evento em que o clube esteve envolvido (Dimic et al., 2018). Ao avançar quanto ao preço das ações dos clubes Herm, CallsenBracker e Kreis (2014) descrevem as informações que os investidores que trabalham a partir das notícias on- 
line sobre os clubes conseguem ter melhor predição sobre o valor de mercado dos clubes.

Quanto ao desempenho dos clubes, Galvão e Dornelas (2017), atestam que os clubes brasileiros são ineficientes quanto ao desempenho financeiro. De outra forma, Sànchez, Fernández e Barajas (2016) inferem que os clubes europeus utilizam, cada vez mais, o planejamento estratégico voltado ao aumento do desempenho financeiro durante a temporada. Esse planejamento pode estar atrelado a conquistas de títulos, em que Gerrard (2005), destaca que esta é uma forma de aumento das receitas na temporada e, de acordo com Barros e Leach (2006) faz com que os clubes sejam, financeiramente, mais eficientes. Contudo, os gestores devem planejar e adequar o desempenho almejado nos campeonatos ao orçamento do clube (Jahara, Mello \& Afonso, 2016), para que não utilizem da venda de imobilizados e jogadores- para obtenção de capital de giro, devido à má gestão (Bosca et al., 2008).

No que concerne ao desempenho financeiro dos clubes, estes podem ser incentivados de diferentes formas, na qual, Ascari e Gagnepan (2006), discorrem que os clubes podem ser incentivados pelo estado. Em complemento, os autores enfatizam que grandes clubes são considerados, em alguns países, como instituições nacionais e, por este motivo, recebem incentivos a nível nacional e regional para continuar suas atividades. Já para Lago, Simmons e Szymanski (2006) a falência de um clube de futebol, diferentemente do mercado privado de alta concorrência, prejudica os outros clubes da mesma liga, dado que diminui o número de jogos e diminui a competitividade e a visibilidade do campeonato e das outras agremiações.

O desempenho dos clubes e a sua classificação nos campeonatos nacionais podem estar relacionado quanto a aspectos de governança corporativa, na qual Silva, Santos e Cunha (2017) discorrem que os clubes pertencentes nas duas principais divisões do futebol brasileiro têm menor número de ressalvas nos relatórios de auditoria. Também, no que diz respeito as boas práticas de governança corporativa, Nazi e Amboni (2008) argumentam que consistem em uma alternativa para problemas quanto a falta de profissionalização dos clubes. Ainda, uma estrutura de governança coorporativa fraca faz com que os acionistas não supervisionem os gerentes, na qual isso pode causar problemas a saúde financeira dos clubes (Andreff, 2007).

\section{RESULTADOS}

Nessa seção, primeiramente, apresenta-se a análise bibliométrica com estudos das variáveis básicas e, em seguida, análise das variáveis avançadas.

\section{Análise Bibliométrica: Estudo das Variáveis Básicas}

Ao analisar os autores dos artigos que formaram o $\mathrm{PB}$, constatou-se que o autor Cleston Alexandre dos Santos teve 3 trabalhos no PB. O autor ainda se destaca com o maior número de redes de autores em seus estudos, ao todo foram 06 redes que o mesmo formou em seus trabalhos. Doutor em Ciências Contábeis e Administração pela Fundação Universidade Regional de Blumenau (FURB) e professor efetivo da Universidade Federal de Mato Grosso do Sul (UFMS), costuma pesquisar nas áreas de contabilidade gerencial/financeira, práticas contábeis, contabilidade e auditoria comportamental, julgamento e tomada de decisão e planejamento e análise de experimentos. Apesar do destaque no PB, não é possível afirmar que este seja o autor mais prolífico do tema.

Quanto às redes de autores do PB, identificou-se que grande parte dos estudos foi realizado por núcleos isolados, entretanto, constatou-se algumas pequenas redes, principalmente realizadas por autores brasileiros, são eles: Cleston Alexandre dos Santos, Andreia Carpes Dani e Paulo Roberto da Cunha, ambos possuem passagens pela Fundação Universidade Regional de Blumenau (FURB) o que pode ter propiciado a execução de trabalhos em conjunto. Tal fato, proporcionou a FURB o feito de instituição de maior destaque no $\mathrm{PB}$, ao totalizar 04 artigos. Destaca-se ainda que esta foi a instituição com maior número de redes entre os artigos do PB.

Ao analisar os países das instituições, percebe-se que a admiração pelo futebol pode impactar na quantidade de estudos. O país com maior número de documentos no PB foi o "país do futebol", Brasil, com 12 artigos; em seguida com 09 trabalhos aparecem os criadores deste esporte, Reino Unido; na terceira posição a Espanha com 06. Embora o Brasil apresente um grande volume de trabalhos no PB, percebe-se que estes não executam redes com outros países, de modo que permite afirmar que a execução dos estudos é interna. Quanto às parcerias, o destaque vai para o Reino Unido, o qual apresentou 06 redes com outros países nos artigos do PB, principalmente com a Europa.

Percebe-se uma difusão em relação às revistas que publicam trabalhos na área de contabilidade para clubes de futebol. Apenas 5 revistas publicaram mais de um trabalho. Deste modo, totalizaram-se 34 
periódicos diferentes para os 52 trabalhos do PB. Destacou-se o Journal of Sports Economics com 09 artigos do PB, assim como a Revista Podium, Sport e Leisure and Tourism Review com 07. Outro ponto interessante foi de que 33 publicações tratavam de Contabilidade Financeira, enquanto 19 abordavam a Contabilidade Gerencial, fato este que demonstra a preocupação da literatura principalmente com os usuários externos.

A maior parte dos estudos analisados que compõem o PB são empíricos, representam $83 \%$ dos estudos listados no PB. Estes artigos em sua grande maioria foram aplicados com dados secundários, os quais analisaram as condições econômico-financeiras dos clubes de determinada região ou liga.

Analisou-se ainda a evolução histórica dos temas abordados nos artigos do PB. Os trabalhos mais antigos buscavam verificar características isoladas, porém, com o passar dos anos, houve uma evolução nas pesquisas da área em que estas começaram a interligar fatores econômicos e desempenho esportivo, ou estilo de gestão, o que levou a avanços significativos nas pesquisas.

O primeiro artigo do PB foi de 1982, de Wray Vamplew o qual fez uma análise sobre a economia da indústria esportiva, abordando a receita de bilheteria do futebol escocês entre os anos de 1890 a 1914. A questão de bilheteria voltou a ser foco com Brandes, Franck e Nüesch (2008), ao estudarem e compararem a presença de astros do futebol e "heróis" locais nos gramados com a presença nas arquibancadas dos estádios, em suas análises investigam o impacto nas rendas de bilheteria.

Simon Chadwick e Jeff Clowes (1998) relatam em um estudo preliminar sobre a aplicação de estratégias de extensão de linha de produtos e marca pelos clubes de futebol da Premier League (Reino Unido). Em 2005, Vincent Couvelaere e André Richelieu também examinar a respeito das marcas dos clubes de futebol, mais especificamente em relação às estratégias e ações que quatro times franceses de futebol implementaram para construir e explorar sua marca. A questão marca e o impacto destas nas finanças dos clubes se destaca nos artigos do PB. Richelieu, Lopez e Desbordes (2008) tiveram como objetivo descrever e explicar como uma equipe pode se tornar uma marca global. Dias e Rossi (2017) identificaram os principais fatores para a internacionalização dos times de futebol via redes estratégicas e abordagens de visão institucional.

Em 2000, Ko de Ruyter e Martin Wetzels desenvolveram uma estrutura de comportamento prósocial para entender e explicar as intenções dos torcedores de comprar ações de seus clubes, a fim de fornecer assistência em momentos de necessidade financeira. Fato este também chamou atenção para o estudo de Zuber, Yiu, Lamb e Gandar (2005), estes verificaram que o comportamento do preço do mercado de times de futebol de capital aberto é muito insensível aos resultados do jogo em termos de retornos e volume de negociação. Berument, Ceylan e Gozpinar (2006) analisaram os três maiores clubes de futebol da Turquia no mercado acionário do país. Deste modo buscaram avaliar o efeito do sucesso do futebol nos retornos do mercado acionário destas equipes. Ainda sobre fãs investidores, Palomino, Renneboog e Zhang (2009) analisaram os clubes de futebol listados na Bolsa de Valores de Londres. Como são investidores atípicos, analisaram o impacto de duas informações: as expectativas dos especialistas sobre os resultados do jogo por meio das probabilidades de apostas e os resultados dos jogos em si e como isto impacta no mercado.

Haugen e Hervik (2002) também demonstraram interesse perante ao mercado de valores dos clubes de futebol, estes apontam que os valores de mercado das equipes de futebol do Reino Unido podem ser descritos por um modelo de regressão notavelmente simples. Este modelo é usado para estimar o valor Premier League. $\mathrm{O}$ mercado acionário realmente foi um dos pontos mais debatidos por estudos que envolvem clubes de futebol. Gannon, Evans e Goddardé (2006) realizaram uma análise dos efeitos a curto prazo dos anúncios em 1996 e 2000 das propostas vencedoras dos direitos de transmissão televisiva ao vivo da English Premiership sobre os preços das ações da British Sky Broadcasting (BSkyB), empresa de transmissão dos jogos, e de vários clubes de futebol e perceberam que as variações do mercado não seguiam um padrão similar, apesar de serem interligados. Demirhan (2013) teve como objetivo investigar se o sucesso esportivo da seleção nacional de futebol da Turquia afeta os retornos do índice de ações da Bolsa de Istambul (BIST). Dimic et al. (2018) pesquisaram a natureza das reações dos preços das ações dos clubes de futebol de capital aberto após os jogos da liga em seis países europeus.

O modelo de utilização de recursos é usado para analisar tanto a capacidade atlética quanto a fidelidade para atingir metas esportivas e financeiras de acordo ao estudo do Gerrard (2005). Kern e Süssmuth (2005) estudaram sobre a eficiência gerencial no futebol alemão da primeira divisão dentro e fora de campo. Em 2006, Barros e Leach analisaram a partir de técnicas e modelos estatísticos 
se o desempenho financeiro poderia impactar e se teria relação com o desempenho esportivo dos clubes de futebol da Liga Inglesa das temporadas entre 19981999 a 2002-2003. Após 10 anos, em 2016, outro artigo do $\mathrm{PB}$ voltou a fazer o comparativo de desempenho nos gramados e nas finanças. Santos, Dani e Hein (2016) analisaram a relação entre o ranking formado pela Confederação Brasileira de Futebol (CBF) e os indicadores econômicofinanceiros das seleções brasileiras de futebol. Um ano mais tarde, Sakinci, Acikalin e Soyguden (2017) analisaram o desempenho financeiro de 22 clubes de futebol listados em vários mercados financeiros europeus e compararam os resultados com os rankings dos clubes da UEFA.

$\mathrm{O}$ ano de 2006 teve três estudos similares, todos eles fizeram análises da situação do futebol de determinado país, principalmente voltados à parte econômica e financeira dos clubes de futebol e da liga nacional. Dejonghe e Vandeweghe (2006) analisaram o futebol belga; Baroncelli e Lago analisaram o futebol italiano; e Ascari e Gagnepan o futebol espanhol. Com uma visão mais geral, Lago, Simmons e Szymanski (2006) se voltaram à crise financeira que o futebol europeu sofre, verificaram ainda que a situação financeira negativa de um clube pode ameaçar a estabilidade financeira dos demais.

Ascari e Gagnepain (2007), analisaram salários, resultados e demandas de torcedores nos estádios de clubes espanhóis e a partir disto perceberam que o aumento dos salários tem motivado a crise financeira no futebol local. Andreff (2007) também estuda a respeito da crise, entretanto, este foca no futebol francês, o qual diferentemente da Espanha é ocasionado, segundo este, devido ao comportamento indisciplinado dos clubes e à falta de transparência e divulgação.

O desempenho financeiro insatisfatório dos clubes de futebol motivou Senaux (2008) a investigar os stakeholders das equipes e relatou que, de forma distinta das empresas, que buscam bons resultados, os clubes se interessam em maximizar sua utilidade e que não se importa com o desempenho econômicofinanceiro. A análise dos resultados econômicos das equipes de futebol profissional também foi objeto de estudo para Boscá, Liern, Martínez e Sala (2008) encontraram que o futebol espanhol tem os mesmos problemas que os evidenciados pelas ligas de futebol italianas e inglesas em que a falta de transparência contábil oculta a crise financeira.

Ainda em 2008, Gammelsæter e Jakobsen realizaram uma pesquisa interessante, uma vez que o objeto de estudo destes foi contra a grande quantidade de estudos sobre o mercado acionário. $\mathrm{O}$ estudo destes parte da observação de que os principais clubes de futebol da Noruega, em contraste com os clubes da maioria dos outros países europeus, não têm permissão para se organizar como empresas públicas limitadas, deste modo, avaliam como os mesmos realizam suas operações e como articulam sua gestão.

Storm (2009) realizou um estudo de caso com o FC København para mostrar que a racionalidade permite atingir resultados financeiros positivos, combinado com desempenho esportivo eficiente. Outro caso de estudo abordando o sucesso econômico retrata a aprendizagem da Major League Soccer (MLS) sobre seu antecessor, a North American Soccer League (NASL), o que retrata padrões de aprendizagem em quatro aspectos: controle, jogadores estrangeiros, relações com a mídia e viabilidade financeira (Francis \& Zheng, 2010).

Frank (2010) apresenta uma análise institucional comparativa de três estruturas de governança de clubes de futebol: empresas privadas de futebol, sociedades anônimas e associações de membros com uma personalidade jurídica própria, quanto ao poder de compra. Skirstad e Chelladurai (2011) mostram como um clube multiesportivo muda durante sua vida organizacional de uma lógica amadora ou voluntária para incorporar múltiplas lógicas simultaneamente com diferentes subunidades alinhadas com diferentes campos organizacionais, por meio da Teoria Institucional. Quanto à governança, Nazi e Amboni (2018) analisaram a relação entre a adoção de práticas de governança corporativa e o desempenho esportivo em clubes de futebol de Caxias do Sul: Esporte Clube Juventude e Sociedade Esportiva e Recreativa de Caxias do Sul, entre 2012 e 2016.

Anagnostopoulos, Byers e Shilburyo (2014) analisaram o processo de tomada de decisão em relação à responsabilidade social corporativa nas fundações de caridade dos clubes de futebol ingleses. Uluyol (2014) realizou uma análise sobre o desempenho financeiro dos clubes da liga turca de futebol. Sánchez, Sánchez-Fernández e Barajas (2016) tiveram como objetivo medir a eficiência dos principais times de futebol europeus sob objetivos financeiros e de ganhos. Jahara, Mello e Afonso (2016) desenvolveram um índice padrão para análise do desempenho financeiro dos clubes de futebol do Brasil que participaram da série A no ano de 2014. Silva, Santos e Cunha (2017) verificaram a relação entre o desempenho econômico-financeiro e os relatórios de auditoria de 2014 de 37 clubes brasileiros de futebol das séries A, B e C. 
Oprean e Oprisor (2014) tiveram como objetivo analisar o motivo da evolução econômica do futebol por meio do ponto de vista contábil e mostrar qual técnica de contabilidade e avaliação é a mais adequada, para apresentar "uma visão verdadeira e justa" nas demonstrações financeiras. De Souza, De Sousa, Nascimento e Bernardes (2016) analisaram a aderência da resolução CFC no $1.429 / 13$ na elaboração e evidenciação das Demonstrações Contábeis dos clubes de futebol da Série A do Campeonato Brasileiro de 2013. Silvestre, Pereira e el Khatib (2016) desenvolveram um estudo sobre o conteúdo dos relatórios de demonstrações financeiras dos clubes de futebol brasileiros. Herm, CallsenBracker e Kreis (2014) descrevem o processo de avaliação da comunidade em geral e a precisão de seus valores de mercado estimados, ainda mostra quais atributos são mais importantes para as avaliações de valor de mercado

O ano de 2017 foi o recordista de publicações no PB, o que totalizaram 9 estudos. Entre estes, Galvão e Dornelas (2017) verificaram o desempenho dos clubes de futebol brasileiros na utilização do atleta como ativo intangível e recurso estratégico para a geração de benefícios econômicos entre 2010 a 2013. Fainshmidt, Smith e Guldiken (2017) analisaram a influência dos fluxos de recursos humanos no desempenho organizacional. Costa et al. (2018) examinaram a percepção dos clubes de futebol profissionais em relação às vantagens competitivas que estes possuem considerando os seus recursos internos e aspectos externos à luz da Teoria Baseada em Recurso (RBV).

Cunha, Santos e Haveroth (2017) descrevem os fatores explicativos contábeis da política de estrutura de capital dos clubes de futebol brasileiros. De Souza, Leite e Seeman (2017) analisaram a possibilidade de um novo estádio para um clube brasileiro de pequeno porte no cenário nacional e qual impacto nas finanças e estrutura de capital do clube. De forma peculiar, Magaz-González, Mallo-Fernández e Fanjul-Suárez (2017) analisaram se é lucrativo jogar na $1^{\mathrm{a}}$ divisão da liga espanhola para qualquer equipe profissional e se todos os clubes da $2^{\mathrm{a}}$ divisão devem aspirar a subir.

Da Silva et al. (2017) verificaram se os clubes de futebol de todo o mundo realizam suas principais transações comerciais (compra e venda de jogadores) com a chamada "Maldição do Vencedor", que seria o fato de que os vencedores do leilão pagam preços mais altos para o bem, acima do seu valor atual. Os valores de mercado dos jogadores também foram investigados por Velema (2018) ao examinar os valores de mercado para jogadores em função de fatores de desempenho e de capital humano em um determinado momento. Cordery, Sim e Baskerville (2018) compararam e contrastaram a Teoria da Dependência de Recursos e a Teoria dos Clubes, ao analisar os fatores que diferenciam os clubes de futebol financeiramente vulneráveis daqueles que não são. Dentre as teorias utilizadas, a Figura 2 apresenta a quantidade de artigos de cada uma.

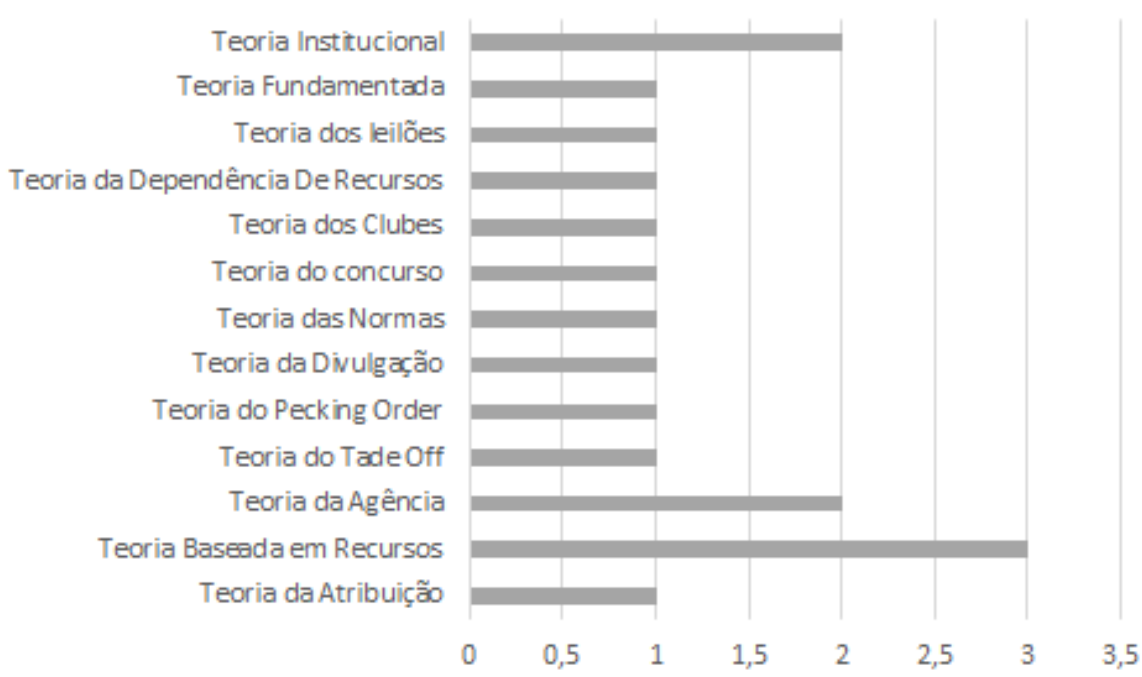

Figura 2. Teorias por artigo do PB

Foram utilizadas 17 teorias pelas pesquisas. Entretanto, em $71,70 \%$ dos artigos, ou seja, 38 estudos não utilizam teoria. Dois estudos utilizaram mais de uma teoria, são eles: Cunha, Santos e Haveroth (2017) com a utilização da Teoria da Agência, Teoria do Trade Off e Teoria do Pecking 
Order; e a pesquisa de Cordery, Sim e Baskerville (2018) com a utilização da Teoria dos Clubes e Teoria da Dependência de Recursos. Destaca-se a Teoria da Visão Baseada em Recursos (RBV), com 03 artigos foi a mais utilizada. Neste contexto, as teorias são oriundas, sobretudo, pelas vertentes econômicas e sociológicas. Assim, não houve nenhuma teoria da vertente psicológica.

\section{Análise Bibliométrica: Estudo das Variáveis Avançadas}

Como última etapa do ProKnow-C, identifica-se as oportunidades de pesquisa com base nas lacunas apresentadas e observadas nos artigos do PB. Esta agenda de pesquisa que será abordada é extraída por meio da análise das limitações e sugestões de pesquisas futuras dos artigos que compõem o fragmento da literatura analisada.

As limitações dos estudos podem ser oriundas das análises dos autores dos estudos analisados que constituem o PB por este estudo analisado, bem como por percepção dos autores ao examinar suas próprias pesquisas.

Vale ressaltar que na análise das variáveis básicas apontou a limitação de análises psicológica. Neste interim, há oportunidade de realização de pesquisas voltadas para o âmbito pessoal nestas instituições, como por exemplo fatores motivacionais, comportamentais, entre outros.
Dos 52 artigos analisados do PB, um montante de 38 não apresentam quaisquer limitações em seus estudos, fato este que deve ser repensado em novas pesquisas, haja vista que não há pesquisas sem limitações, seja por escolhas dos pesquisadores, ferramentas utilizadas, amostra e afins.

Dentre todas as limitações apontadas pelos pesquisadores nos estudos analisados do fragmento da literatura, destaca-se o tamanho amostral (Boscá et al., 2008; De Souza et al., 2016; Santos, Dani, \& Hein, 2016; Cunha, Santos, \& Haveroth, 2017; Silva, Santos \& Cunha., 2017; Dias, \& Rossi, 2017; Fainshmidt, Smith, \& Guldiken, 2017; Galvão, \& Dornelas, 2017; Cordery, Sim, \& Baskerville, 2018; Costa et al., 2018). De forma particular, Boscá et al. (2008), Cunha, Santos e Haveroth (2017), Galvão e Dornelas (2017) e Costa et al. (2018) apontaram que não há regularidade nas publicações dos relatórios financeiros dos clubes brasileiros, além de dificuldade para sua obtenção. Galvão e Dornelas (2017) mencionaram a necessidade de análise sobre características organizacionais como expertise do gerente, sistema de controle interno relacionadas ao desempenho organizacional dos clubes. Vale destacar que grande número de estudos não apresenta limitações. Contudo, 52\% dos artigos do PB descreveram sugestões de pesquisas futuras. Na Tabela1, apresenta-se as sugestões extraídas do fragmento da literatura.

\section{Tabela 1}

Síntese das sugestões de pesquisas futuras dos artigos do PB

\begin{tabular}{|c|l|}
\hline Autor (Ano) & \multicolumn{1}{c|}{ Sugestão } \\
\hline Ruyter e Wetzels (2000) & $\begin{array}{l}\text { O efeito da articulação normativa em questionários deve ser investigado para garantir a } \\
\text { validade dos resultados da pesquisa. Além disso, também vale a pena estudar as intenções } \\
\text { de compra de ações em relação às ações de empresas comerciais e compará-las com as } \\
\text { intenções de compra de ações dos torcedores de futebol. }\end{array}$ \\
\hline Kern e Süssmuth (2005) & $\begin{array}{l}\text { Considerar modelos da Análise Envoltória de Dados (DEA) que permitam resultados } \\
\text { multivariados (total e doméstico / atlético e econômico) e a incorporação de um elemento } \\
\text { estocástico; ver Terra et al. (1993). }\end{array}$ \\
\hline $\begin{array}{c}\text { Gerrard (2005) } \\
\text { A análise macro de eficiência esportiva e financeira deve ser complementada por análise } \\
\text { micro como por estudos de caso que forneçam uma investigação detalhada das } \\
\text { organizações. }\end{array}$ \\
\hline $\begin{array}{c}\text { Barros e Leach (2006) } \\
\text { Callejo e Forcadell } \\
\text { (2006) }\end{array}$ & $\begin{array}{l}\text { Identificar outros fatores determinantes da ineficiência financeira entre os clubes da } \\
\text { Premier League. }\end{array}$ \\
\hline $\begin{array}{l}\text { Comparar a excelência organizacional do Real Madrid com outros importantes clubes de } \\
\text { futebol europeu ou organizações esportivas com estratégia de marca. }\end{array}$ \\
\hline
\end{tabular}




\begin{tabular}{|c|c|}
\hline $\begin{array}{l}\text { Brandes, Franck e } \\
\text { Nüesch (2008) }\end{array}$ & $\begin{array}{l}\text { Analisar se o número de torcedores varia de acordo com o número de superstars da equipe, } \\
\text { o que permite quantificação mais precisa do valor desta externalidade. }\end{array}$ \\
\hline Senaux (2008) & $\begin{array}{l}\text { Estudos de caso mais aprofundados e longitudinais devem permitir analisar a presença de } \\
\text { múltiplos stakeholders. Análise da governança dos clubes europeus que para apontar as } \\
\text { diferenças em outros contextos, pode fornecer informações úteis para explicar o } \\
\text { desempenho relativo dos clubes. }\end{array}$ \\
\hline $\begin{array}{l}\text { Richelieu, Lopez e } \\
\text { Desbordes (2008) }\end{array}$ & $\begin{array}{l}\text { Mais estudos de caso para validar o modelo e também traçar paralelos entre diferentes } \\
\text { continentes e diferentes esportes. }\end{array}$ \\
\hline Francis e Zheng (2010) & $\begin{array}{l}\text { Replicação com uma amostra com características diferentes. Identificar as condições } \\
\text { moderadoras que capacitam ou diminuem o aprendizado com os fracassos dos outros. }\end{array}$ \\
\hline $\begin{array}{l}\text { Skirstad e Chelladurai } \\
\qquad(2011)\end{array}$ & $\begin{array}{l}\text { Investigar se padrões evolucionários similares de lógicas institucionais surgiram em outros } \\
\text { contextos. Devem também verificar até que ponto os reguladores nacionais em outros } \\
\text { países são flexíveis para permitir que seus membros adaptem suas estruturas e processos } \\
\text { para que sejam consistentes com as regulamentações nacionais e com os imperativos das } \\
\text { múltiplas esferas institucionais em que operam. }\end{array}$ \\
\hline Garcia e Welford (2013) & $\begin{array}{l}\text { Analisar as diferentes dimensões do envolvimento do patrocinador com a governança e } \\
\text { como elas interagem com a autenticidade, lealdade e consumo. Pesquisar como, por que e } \\
\text { o que os torcedores fazem em relação à governança, na tentativa de construir uma base de } \\
\text { evidências mais forte. }\end{array}$ \\
\hline $\begin{array}{l}\text { Anagnostopoulos, Byers } \\
\text { e Shilbury (2014) }\end{array}$ & $\begin{array}{l}\text { Examinar a aplicabilidade da "transcendência avaliável" e seus conceitos associativos fora } \\
\text { do contexto esportivo, uma vez que trataram da responsabilidade social. }\end{array}$ \\
\hline $\begin{array}{l}\text { Herm, Callsen-Bracker e } \\
\text { Kreis (2014) }\end{array}$ & $\begin{array}{l}\text { Incluir variáveis adicionais no modelo que pertencem a um desses dois blocos (variáveis } \\
\text { de talento } \mathrm{x} \text { variáveis externas) para avaliação de mercado. }\end{array}$ \\
\hline De Souza et al. (2016) & $\begin{array}{l}\text { Recomenda-se realizar pesquisa sobre o nível de evidenciação dos demonstrativos } \\
\text { contábeis dos clubes de futebol com base na Resolução CFC no } 1.429 / 2013 \text { que abrange as } \\
\text { Séries B, C e D do campeonato brasileiro. Estabelecer um comparativo de disclosure entre } \\
\text { os clubes brasileiros consoantes a NBC ITG } 2003 \text { e clubes estrangeiros. }\end{array}$ \\
\hline $\begin{array}{l}\text { Silvestre, Pereira e El } \\
\quad \text { Khatib (2016) }\end{array}$ & $\begin{array}{l}\text { Ampliar a amostra estudada sobre as demonstrações financeiras dos clubes de futebol } \\
\text { brasileiros; Realizar estudo com base no conteúdo dos parágrafos de ênfase, visto que quase } \\
\text { a totalidade dos clubes o apresentam. }\end{array}$ \\
\hline $\begin{array}{l}\text { Jahara, Mello e Afonso } \\
\text { (2016) }\end{array}$ & $\begin{array}{l}\text { Sugere-se o aperfeiçoamento e desenvolvimento de novos indicadores como forma de } \\
\text { mitigar problemas de gestão e desempenho. }\end{array}$ \\
\hline $\begin{array}{l}\text { Santos, Dani e Hein } \\
\qquad(2016)\end{array}$ & $\begin{array}{l}\text { Sugere-se a inclusão das variáveis tamanho da torcida e tamanho da população da cidade- } \\
\text { sede, a ampliação do período de análise e a inclusão de outros países pois possuem } \\
\text { estruturas financeiras bem diferenciadas, como também campeonatos com formatos } \\
\text { diferentes. }\end{array}$ \\
\hline Dias e Rossi (2017) & $\begin{array}{l}\text { Concentrar as análises em apenas uma das capacidades internas das organizações } \\
\text { desportivas sem fins lucrativos, de modo a aprofundar os conhecimentos e achados. }\end{array}$ \\
\hline $\begin{array}{l}\text { Fainshmidt, Smith e } \\
\text { Guldiken (2017) }\end{array}$ & $\begin{array}{l}\text { Estudar a impacto cumulativo dos fluxos de recursos humanos durante períodos de tempo } \\
\text { mais longos. }\end{array}$ \\
\hline $\begin{array}{l}\text { Cunha, Santos e Haveroth } \\
\text { (2017) }\end{array}$ & $\begin{array}{l}\text { Ampliação do número da amostra, no número de períodos de análise, como também, uma } \\
\text { análise comparativa entre os clubes da série A, B e C para estudos de suas estruturas de } \\
\text { capital. }\end{array}$ \\
\hline
\end{tabular}




\begin{tabular}{|c|c|}
\hline Galvão e Dornelas (2017) & $\begin{array}{l}\text { Comparar o desempenho dos clubes brasileiros com a apresentada por clubes } \\
\text { internacionais. Verificar quais variáveis tornam o clube eficiente em gerar benefícios } \\
\text { econômicos por meio do investimento em ativo intangível. Estudos de caso em clubes para } \\
\text { verificar quais os objetivos que estes possuem ao investir em atletas, quais os retornos } \\
\text { econômicos e financeiros esperados e como se dá o gerenciamento deste recurso, a fim de } \\
\text { que ele seja utilizado com a máxima eficiência. }\end{array}$ \\
\hline $\begin{array}{l}\text { Silva, Santos e Cunha } \\
\text { (2017) }\end{array}$ & $\begin{array}{l}\text { Explorar a existência de relação entre o desempenho econômico-financeiro e os tipos de } \\
\text { relatórios de auditoria de clubes de países da Europa. }\end{array}$ \\
\hline Da Silva et al. (2017) & $\begin{array}{l}\text { Sugere-se para a realização de futuras pesquisas que o comportamento seja investigado } \\
\text { considerando uma série temporal, buscando-se verificar se é sistematicamente realizado } \\
\text { pelos mesmos clubes de futebol verificados nesta pesquisa. Sugere-se ainda a investigação } \\
\text { dos clubes nacionais das séries A e B, que realizam transações de compra e venda de atletas } \\
\text { com valores expressivos. }\end{array}$ \\
\hline Costa et al. (2018) & $\begin{array}{l}\text { Outros itens poderiam medir melhor esse construto, portanto, novos itens devem ser criados } \\
\text { em pesquisas futuras, o que permitiria a análise da percepção de patrocínio dos clubes em } \\
\text { relação à vantagem competitiva. Adição de diferentes recursos internos ou aspectos } \\
\text { externos não contemplados neste estudo poderiam ser considerados. }\end{array}$ \\
\hline Nazi e Amboni (2018) & $\begin{array}{l}\text { Pesquisas sobre governança e demais assuntos referentes à administração de entidades } \\
\text { esportivas em outros clubes brasileiros, para identificar os impactos do PROFUT e demais } \\
\text { regulações em médio e longo prazos. }\end{array}$ \\
\hline $\begin{array}{l}\text { Cordery, Sim e } \\
\text { Baskerville (2018) }\end{array}$ & $\begin{array}{l}\text { Realização de estudos de caso ou outras abordagens para identificação e caracterização dos } \\
\text { clubes financeiramente vulneráveis. }\end{array}$ \\
\hline Velema (2018) & $\begin{array}{l}\text { Analisar como os jogadores se movem no futebol profissional e como se prepararam para } \\
\text { a sua aposentadoria. Investigar como a mobilidade afeta o valor de mercado dos jogadores } \\
\text { que começaram sua carreira em países mais periféricos do futebol mundial. }\end{array}$ \\
\hline
\end{tabular}

As informações demonstradas no Quadro 1 podem auxiliar pesquisadores na ampliação de conhecimento sobre a área de contabilidade em clubes de futebol. As sugestões de pesquisas devem, portanto, ser captadas como oportunidades a serem exploradas. Além das sugestões apresentadas pelos autores dos artigos que compõem o PB, por meio de uma análise geral dos materiais, aponta-se a lacuna de estudos com a vertente psicológica, com olhar individual em clubes de futebol que envolve a contabilidade.

\section{CONSIDERAÇÕES FINAIS}

O objetivo foi analisar as características das investigações nacionais e internacionais em relação a um fragmento de literatura sobre a sobre a literatura Contábil em Clubes de Futebol, ao ter como intenção gerar conhecimento e identificar lacunas para as possibilidades de futuras investigações. Desenvolveu-se o presente estudo com o uso do ProKnow-C que resultou em 52 artigos, analisados por meio da bibliometria básica e da avançada.

Os resultados descritos quanto às variáveis básicas permitem identificar que a maioria dos estudos são empíricos com o uso de dados secundários. As pesquisas consideraram as condições econômicofinanceiras dos clubes por ser dados disponibilizados de forma obrigatória em detrimento a investigações de âmbito qualitativo. Contudo, houve evolução da área em que começaram a interligar estes fatores econômicos e desempenho esportivo. Em termos de teoria, foram identificadas 17 que pertencem as vertentes econômica e sociológica. Entre elas, destaca-se a Teoria da Visão Baseada em Recursos (RBV) que foi a mais utilizada. Neste sentido, percebe-se oportunidade de estudos sob a lente de outras vertentes e também dar continuidade nestas teorias encontradas por ainda serem de uso incipiente neste tipo de estudo.

A análise das variáveis avançadas descreve as oportunidades de pesquisa com base nas lacunas ditas por meio das limitações e sugestões destes estudos. Entre as limitações, destacam-se a irregularidade das publicações dos relatórios financeiros e dificuldade na sua obtenção. Este achado pode descrever a dificuldade em termo de acessibilidade aos clubes de futebol, no qual a maioria dos estudos se limitam 
apenas aos dados secundários que são divulgados. Dentre as sugestões, citam-se investigar as características organizacionais, como expertise do gestor (Presidente), sistema de controle gerencial, outros fatores determinantes à ineficiência financeira, como os jogadores se preparam para sua aposentaria, realização de estudo de caso em clubes para verificar quais os objetivos que estes possuem ao investir em atletas, quais os retornos econômicos e financeiros esperados e como se dá o gerenciamento deste recurso.

Adicionalmente, com o intuito de promover avanços nesta área de conhecimento, com base nas lacunas identificadas, elencam-se desafios para os gestores dos clubes de futebol. Entende-se a necessidade de abertura dos clubes de futebol para pesquisas acadêmica, o que certamente contribuirão para o avanço acadêmico e também em âmbito profissional. A maioria das pesquisas apresenta discussões sobre o comportamento do preço de ações dos clubes de futebol.

Neste interim, torna-se relevante refletir quanto abertura de capital para negociar ações ao reconhecer possibilidade de captação de novos recursos/investimentos. Por fim, é salutar que evidenciem os relatórios financeiros de forma regular e um meio que possibilite fácil obtenção aos pesquisadores e ao público de forma geral.

\section{REFERÊNCIAS}

Anagnostopoulos, C., Byers, T., \& Shilbury, D. (2014). Corporate social responsibility in professional team sport organisations: Towards a theory of decisionmaking. European Sport Management Quarterly, 14(3), 259-281. [PB]

Abosag, B., Roper, S., \& Hind, D. (2012). Examining the relationship between brand emotion and brand extension among supporters of professional football clubs. European Journal of Marketing, 46(9), 1233-1251.

Andreff, W. (2007). French football: A financial crisis rooted in weak governance. Journal of Sports Economics, 8(6), 652-661. [PB]

Ascari, G., \& Gagnepain, P. (2006). Spanish football. Journal of sports economics, 7(1), 76-89. [PB]

Ascari, G., \& Gagnepain, P. (2007). Evaluating rent dissipation in the Spanish football industry. Journal of Sports Economics, 8(5), 468-490. [PB]
De forma geral, o estudo buscou identificar oportunidades de novas pesquisas na área de clubes de futebol que estão abertas na literatura, bem como, com base na literatura analisada, a necessidade de melhoria na gestão dos clubes de futebol, voltada tanto ao desempenho esportivo quanto financeiro e econômico.

Não se pretende com esta pesquisa esgotar a discussão sobre o assunto, ao ter em vista que outros estudos necessitam ser realizados e diferentes abordagens podem divergir dos resultados. Algumas limitações da investigação podem ser citadas, como a formação do PB restringir-se às publicações em periódicos indexados nas bases de dados do portal da CAPES; artigos publicados em revistas cientificas indexada nas bases selecionadas; e a análise dos artigos do PB, com relação às variáveis investigadas, foi informada pelo julgamento e interpretação dos autores. Ao visar investigações futuras, sugere-se (i) a ampliação desta pesquisa a outras bases de dados e (ii) o desenvolvimento de pesquisas que busquem preencher as lacunas, aproveitar as oportunidades e os desafios apontados.

\section{AGRADECIMENTOS}

O presente trabalho foi realizado com apoio da Coordenação de Aperfeiçoamento de Pessoal de Nível Superior - Brasil (CAPES) - Código de Financiamento 001.

Baroncelli, A., \& Lago, U. (2006). Italian football. Journal of sports economics, 7(1), 13-28. [PB]

Barros, C. P., \& Leach, S. (2006). Analyzing the performance of the English FA Premier League with an econometric frontier model. Journal of Sports Economics, 7(4), 391-407. [PB]

Berument, H., Ceylan, N. B., \& Gozpinar, E. (2006). Performance of soccer on the stock market: Evidence from Turkey. The Social Science Journal, 43(4), 695-699. [PB]

Boscá, J. E., Liern, V., Martínez, A., \& Sala, R. (2008). The Spanish football crisis. European sport management quarterly, 8(2), 165-177. [PB]

Brandes, L., Franck, E., \& Nüesch, S. (2008). Local heroes and superstars: An empirical analysis of star attraction in German soccer. Journal of Sports Economics, 9(3), 266-286. [PB]

Callejo, M. B., \& Forcadell, F. J. (2006). Real Madrid football club: A new model of business 
organization for sports clubs in Spain. Global Business and Organizational Excellence, 26(1), 5164. [PB]

Castro, C. M. (1977). A prática da pesquisa. São Paulo: McGraw-Hill do Brasil.

Chadwick, S., \& Clowes, J. (1998). The use of extension strategies by clubs in the English Football Premier League. Managing Leisure, 3(4), 194-203. [PB]

Cordery, C. J., Sim, D., \& Baskerville, R. F. (2018). Financial vulnerability in football clubs: learning from resource dependency and club theories. [PB]

Costa, M. F. D., Costa, C. E., Angelo, C. F. D., \& Moraes, W. F. A. D. (2018). Perceived competitive advantage of soccer clubs: a study based on the resource-based view. RAUSP Management Journal, 53(1), 23-34. [PB]

Couvelaere, V., \& Richelieu, A. (2005). Brand strategy in professional sports: The case of French soccer teams. European Sport Management Quartely, 5(1), 23-46. [PB]

Cunha, P. R., dos Santos, C. A., \& Haveroth, J. (2017). Accounting explanatory factors of capital structure policy of brazilian soccer clubs. Podium: Sport, Leisure and Tourism Review, 6(1), 1-22. [PB]

Da Silva, J. P., Santos, P. S. A., de Souza, E. S., \& Dani, A. C. (2017). Winner's curse: an analysis of transactions happening in soccer clubs. Podium: Sport, Leisure and Tourism Review, 6(1), 22-43. [PB]

Dantas, M. G. S., \& Boente, D. R. (2011). A eficiência financeira e esportiva dos maiores clubes de futebol europeus utilizando a análise envoltória de dados. Revista de Contabilidade e Organizações, 5(13), 75-90.

Dejonghe, T., \& Vandeweghe, H. (2006). Belgian football. Journal of sports economics, 7(1), 105-113. [PB]

Demirhan, D. (2013). Stock market reaction to national sporting success: case of Istanbul stock exchange. Pamukkale Journal of Sport Sciences, 4(3), 107-121. [PB]

De Souza, A. G., de Sousa, W. D., do Nascimento, J. C. H. B., \& Bernardes, J. R. (2016). Disclosure of financial statements: a study on the level of accounting disclosure of brazilian soccer clubs in 2013. Podium: Sport, Leisure and Tourism Review, 5(3), 1-20. [PB]

De Souza, E., Leite, L., \& Seemann, J. D. S. (2017). The Chape And The New Arena Conda: Dream Or Reality?. Revista Gestao Organizacional, 10(2), 80-102. [PB]

Dias, I. R. R., \& Rossi, G. B. (2017). How far is World Champion from World Class? Institutional effects on a Brazilian non-profit sports organization. Brazilian Business Review, 24. [PB]

Dimic, N., Neudl, M., Orlov, V., \& Äijö, J. (2018). Investor sentiment, soccer games and stock returns. Research in International Business and Finance, 43, 90-98. [PB]

Dutra, A., Ripoll-Feliu, V. M., Fillol, A. G., Ensslin, S. R., \& Ensslin, L. (2015). The construction of knowledge from the scientific literature about the theme seaport performance evaluation. International Journal of Productivity and Performance Management, 64(2), 243-269.

Ensslin, S. R., Ensslin, L., Imlau, J. M., \& Chaves, L. C. (2014). Processo de mapeamento das publicações científicas de um tema: portfólio bibliográfico e análise bibliométrica sobre avaliação de desempenho de cooperativas de produção agropecuária. Revista de Economia e Sociologia Rural, 52(3), 587-608.

Fainshmidt, S., Smith, A., \& Guldiken, O. (2017). Orchestrating the flow of human resources: Insights from Spanish soccer clubs. Strategic Organization, 15(4), 441-460. [PB]

Francis, J., \& Zheng, C. (2010). Learning vicariously from failure: The case of major league soccer and the collapse of the North American Soccer League. Group \& Organization Management, 35(5), 542-571. [PB]

Franck, E. (2010). Private firm, public corporation or member's association governance structures in European football. International Journal of Sport Finance, 5(2), 108. [PB]

Galvão, N., \& Dornelas, J. (2017). Análise de desempenho na geração de benefícios econômicos 
dos clubes de futebol brasileiros: o uso do atleta como recurso estratégico e ativo intangível. Revista Contemporânea de Contabilidade, 14(32), 21-47. [PB]

Gammelsæter, H., \& Jakobsen, S. E. (2008). Models of organization in Norwegian professional soccer. European Sport Management Quarterly, 8(1), 1-25. [PB]

Gannon, J., Evans, K., \& Goddard, J. (2006). The stock market effects of the sale of live broadcasting rights for English premiership football: An event study. Journal of Sports Economics, 7(2), 168-186. [PB]

Gerrard, B. (2005). A resource-utilization model of organizational efficiency in professional sports teams. Journal of Sport Management, 19(2), 143-169. [PB]

Haugen, K. K., \& Hervik, A. (2002). Estimating the value of the Premier League or the worlds most profitable investment project. Applied Economics Letters, 9(2), 117-120. [PB]

Herm, S., Callsen-Bracker, H. M., \& Kreis, H. (2014). When the crowd evaluates soccer players' market values: Accuracy and evaluation attributes of an online community. Sport Management Review, 17(4), 484-492. [PB]

Holanda, A. P., Meneses, A. F. D., Mapurunga, P. V. R., De Luca, M. M. M., \& Coelho, A. C. D. (2012). Determinantes do nível de disclosure em clubes brasileiros de futebol. Revista de Contabilidade do Mestrado em Ciências Contábeis da UERJ, 17(1), 2-17.

Jahara, R. C., Mello, J. A. V. B., \& da Gama Afonso, H. C. A. (2016). Proposal for standard index and analysis of financial performance in 2014 of brazilian soccer clubs of serie A. Podium: Sport, Leisure and Tourism Review, 5(3), 20-41. [PB]

Kern, M., \& Süssmuth, B. (2005). Managerial efficiency in German top league soccer: an econometric analysis of club performances on and off the pitch. German Economic Review, 6(4), 485-506. [PB]

Lago, U., Simmons, R., \& Szymanski, S. (2006). The financial crisis in European football: An introduction. [PB]
Magaz-González, A. M., Mallo-Fernández, F., \& Fanjul-Suárez, J. L. (2017). Is profitable to play in spanish soccer premier league; es rentable jugar en primera división de futbol?. International Journal of Medicine and Science of Physical Activity and Sport, 17(65), 1-26. [PB]

Marçal, R. R. (2018). Contabilidade Desportiva: Um estudo sobre o impacto dos investimentos na formação de atletas nas marcas dos clubes brasileiros de futebol. Revista Mineira de Contabilidade, 19(2), 68-76.

Nazi, R. M., \& Amboni, N. (2018). Governança e Futebol: Um Estudo em Clubes de Caxias do Sul (Governance and Soccer: A Study in Clubs From Caxias Do Sul). PODIUM Sport, Leisure and Tourism Review, 7(2), 240-259. [PB]

Oprean, V. B., \& Oprisor, T. (2014). Accounting for soccer players: capitalization paradigm vs. Expenditure. Procedia Economics and Finance, 15, 1647-1654. [PB]

Palomino, F., Renneboog, L., \& Zhang, C. (2009). Information salience, investor sentiment, and stock returns: The case of British soccer betting. Journal of Corporate Finance, 15(3), 368-387. [PB]

Prodanov, C. C., \& de Freitas, E. C. (2013). Metodologia do Trabalho Científico: Métodos e Técnicas da Pesquisa e do Trabalho Acadêmico. 2. ed. Editora Feevale.

Richelieu, A. (2008). The internationalisation of a sports team brand: The case of European soccer teams. International journal of sports marketing and sponsorship, 10(1), 23-38. [PB]

Ruyter, K., \& Wetzels, M. (2000). With a little help from my fans-Extending models of pro-social behaviour to explain supporters' intentions to buy soccer club shares. Journal of Economic Psychology, 21(4), 387-409. [PB]

Santos, C. A., Dani, A. C., \& Hein, N. (2016). Relationship between the brazilian soccer confederation rankings and the economical-financial indicators of soccer teams. Podium: Sport, Leisure and Tourism Review, 5(3), 41-60. [PB]

Sakinc, I., Acikalin, S., \& Soyguden, A. (2017). Evaluation of the Relationship between Financial 
Performance and Sport Success in European Football. Journal of Physical Education and Sport, 17, 16. [PB]

Sánchez, L. C., Sánchez-Fernández, P., \& Barajas, Á. (2016). Objetivos financieros y deportivos en la eficiencia del fútbol europeo. Revista de psicología del deporte, 25(1). [PB]

Senaux, B. (2008). A stakeholder approach to football club governance. International Journal of Sport Management and Marketing, 4(1), 4. [PB]

Silva, T. B. J., Santos, C. A., \& da Cunha, P. R. (2017). The relationship between economic-financial performance and Brazilian soccer teams audit reports. Revista De Gestao, Financas E Contabilidade, 7(3), 177-201. [PB]

Silvestre, A. O., Pereira, F. A., \& El Khatib, A. S. (2016). Independent Audit: A Study About The Content Of Brazilian Football Clubs Financial Statements Reports. Revista Contabilidade $E$ Controladoria-RC C, 8(2), 90-107. [PB]

Skirstad, B., \& Chelladurai, P. (2011). For 'love'and money: A sports club's innovative response to multiple logics. Journal of Sport Management, 25(4), 339-353. [PB]

Storm, R. K. (2009). The rational emotions of FC København: a lesson on generating profit in professional soccer. Soccer \& Society, 10(3-4), 459476. [PB]

Thiel, G. G., Ensslin, S. R., \& Ensslin, L. (2017). Street Lighting Management and Performance Evaluation: Opportunities and Challenges. Lex Localis, 15(2), 303-328.
Uluyol, O. (2014). Süper Lig Futbol Kulüplerinin Finansal Performans Analizi/Financial Performance Analysis Of Super League Football Clubs. Journal of Yaşar University, 9(34), 5716-5731. [PB]

Valmorbida, S. M. I., Ensslin, S. R., Ensslin, L., \& Ripoll-Feliu, V. M. (2014). Avaliação de desempenho para auxílio na gestão de universidades públicas: análise da literatura para identificação de oportunidades de pesquisas. Revista Contabilidade, Gestão e Governança, 17(3).

Valmorbida, S. M. I., Ensslin, S. R., Ensslin, L., \& Ripoll-Feliu, V. M. (2016). Rankings universitários mundiais. Que dizem os estudos internacionais?. REICE. Revista Iberoamericana sobre Calidad, Eficacia y Cambio en Educación, 14(2), 5-29.

Vamplew, W. (1982). The Economics of a Sports Industry: Scottish Gate- Money Football, 1890-1914 1. The Economic History Review, 35(4), 549-567. [PB]

Velema, T. A. (2018). Upward and downward job mobility and player market values in contemporary European professional football. Sport Management Review. [PB]

Zuber, R. A., Yiu, P., Lamb, R. P., \& Gandar, J. M. (2005). Investor-fans? An examination of the performance of publicly traded English Premier League teams. Applied Financial Economics, 15(5), 305-313. [PB] 